\title{
HOW WORKPLACE CONDITION AFFECTS HEALTHCARE WORKERS: ASSESSMENT AT TERTIARY HOSPITALS
}

\author{
Shaik Farid $\mathrm{AW}^{1,2}$, Ahmad Rasdan Ismail ${ }^{3,4}$ and Rohayu $\mathrm{O}^{5}$
}

${ }^{1}$ Department of Emergency Medicine, School of Medical Sciences, Universiti Sains Malaysia, Kubang Kerian, Malaysia.

${ }^{2}$ Hospital Universiti Sains Malaysia, Kubang Kerian, Kelantan, Malaysia

${ }^{3}$ Faculty of Creative Technology and Heritage, Universiti Malaysia Kelantan, Campus Bachok, Bachok, Kelantan, Malaysia

${ }^{4}$ Center of Management Environment, Occupational Safety and Health (CMeOSH), Universiti Malaysia Kelantan, Bachok, Kelantan, Malaysia

${ }^{5}$ Kolej Kemahiran Tinggi MARA Pasir Mas, Lubok Jong, 17000 Pasir Mas, Kelantan, Malaysia

* Corresponding author: Shaik Farid AW

Email address: drsfarid@usm.my

\begin{abstract}
Complaint of pain due to work related musculoskeletal disorder at workplace is nothing new. Nevertheless, in Malaysia, the data leading to this is near to none, when healthcare industry is concerned. The purpose of this article is to evaluate the current physical condition at red zone of accident and emergency department at selected hospitals and has the current condition contribute to the work-related musculoskeletal disorder among healthcare personnel. The study is conducted at five red zones of accident and emergency department of Malaysia tertiary hospitals. Before conducting the study, ethical approval has been obtained from ethical committee of Kementerian Kesihatan Malaysia. Method used in this study is workplace assessment, which allows first-hand experienced to determine and evaluate the real condition of red zone at selected hospitals. Duration of twelve months is required to complete the assessment. During the workplace assessment, the lighting at red zone (focusing on bed area), the bed space, arrangement of equipment and height of monitors are observed, measured and recorded. Result show, every red zone is unique with its own layout and design. There is no standardization among all the red zones involved. Existing guideline for physical condition of red zone of accident and emergency does not exist. Thus, relationship between physical condition of existing red zone and whether it causes work related musculoskeletal disorder must be discussed in length.
\end{abstract}

Keywords: workplace assessment, healthcare workers

\section{INTRODUCTION}

Healthcare workers are at risk of musculoskeletal hazards due to poor working conditions 1-2. Musculoskeletal disorders have been reported almost from all industry including agricultural ${ }^{3}$, manufacturing 4-5, and furniture making industry ${ }^{6}$. The study aims to investigate how the existing condition at accident and emergency department of Malaysia Hospital might lead to potential risk of musculoskeletal disorder among healthcare workers. The study aims to investigate how the existing condition at accident and emergency department might lead to potential risk of musculoskeletal disorder among healthcare workers. Three factors considered in the study are lighting, bed space and monitor height. Each of this is measured for every red zone involved in the study.

The important of natural lighting has been acknowledged and many researchers have shown interest in this area. Proper lighting at hospital not only significant in reducing error, increase awareness, but as tool for healing. Poor lighting in intensive care unit has been identified as one of factors that lead to poor working condition, leading to increase stress among patients and healthcare worker ${ }^{7-8}$. Although the aim of this paper is to explore the perspective from healthcare workers, one cannot deny that if the same environment causes unhealthy affect to patients, that same affect might also be experienced by healthcare workers. An interesting finding in a study conducted in Greek Hospital conclude that healthcare workers demand proper lighting during working ${ }^{9}$.

Another physical element considered in the study is bed space area. Bed space area is defined as area around individual bed, whereby, it should provide privacy to the patients ${ }^{10}$. The designing for the suitable bed space can be challenging due to the facts that in healthcare, the numbers of people and tasks conducted at the bed space are varies. Certain procedures might involve a team of people and multiple tools and monitors at one time. It is common to see numbers of trolley, monitor and tools located around bed area, especially in red zone. Although the aim is to ease of locate during emergency, the space is crowded most of the time. Despite the bed space area was not a priority during the era of the department development previously; the 
creativity of the current management team is a vital part.

Monitors are widely used in the red zone. Patients' vital signs are read and monitored via these monitors located beside patient's bed. Most of the time, monitors are fixed and not adjustable. It is interesting to investigate the height of the monitors. Although it might seem less significant, but the numbers of healthcare workers have to look, read and record reading from the monitor might have impact on discomfort to them. This element has less attention compares to lighting and bed spaces when researches are concerned.

\section{METHODS}

This In this study, six tertiary hospitals are involved. Tertiary hospital is a referral hospital, where district hospitals send difficult cases for further treatment. At tertiary hospitals, special medical fraternity such as neurology is available. Before conducting the study, ethical approval is requested from Ministry of Health. An online application is made for both ethical approvals. The study is only conducted after the application for ethical approval is approved.

This study is conducted via a walkthrough at all the selected red zones. Observation at workplace is adapted and used in this study. The benefit of observations at workplace allows better insight about how the absolute condition during the working hour. During the observation, required measurement for lighting, bed space and monitor's height are measures and recorded

\section{RESULTS}

\section{Lighting}

Lighting is measured using handy Flux Meter HD 450. The lighting assessment is done on patient's bed, where imaginary grids are drawn on the bed. The lux meter is placed on the centre of the grid and reading is recorded. This method is also suggested in the Guidelines on Occupational and Safety and Health for Lighting at Workplace 2018. During the observation, one important finding to note that, all red zones participated are lighted by artificial lighting. None of the red zone used natural lighting and observation found, there is no windows at all or small window panels in the red zone. The light source is mainly from the standard lighting according to building specification. Results obtained from the measurement is presented in the table 1.
Table 1: Luminance at Red Zone

\begin{tabular}{cc}
\hline Hospital & Luminance (lux) \\
\hline A & 414 \\
B & 372.4 \\
C & 162.7 \\
D & 368.7 \\
E & 174.7 \\
\hline
\end{tabular}

It is important to note that different red zone, has different lux reading. The luminance ranges from 162.7 lux to 414 lux. Hospital A is properly lit compared to Hospital C. To date, there is guideline available on how much should be the lux at red zone, specifically. However, Guidelines on Occupational and Safety and Health for Lighting at Workplace 2018 suggested for simple examination, 300 lux is required. Examination room in general should be at least 500 lux. Based on Table 1, Hospital C and E are not even in the optimum condition to conduct any examination to the patients. Poor lighting lead to poor body postures such as bending especially when conducting procedure such as phlebotomy. Healthcare workers need to adjust their postures and bend in order to get the task done. Even though there is additional lighting mounted, observation shown that, healthcare workers do not use the light when performing procedures. Healthcare workers over the working experiences, adapt to the poorly lit environment even though causing discomfort to them.

\section{Bed space}

Similar with the lighting, there is also no standardization on measurement of bed space at red zone. More than often, the numbers of stretchers and bed are doubled than the designed capacity, thus making the bed space even smaller. The department absorb the patients by providing temporary bed or stretcher, thus making the bed space even smaller and more crowded. The condition worsens with relatives around the bed and multiple equipment. For example, manualhandling activities such as patient lifting (adult patient) require more than four healthcare workers. The healthcare workers work in awkward postures when doing this task. Activities such as positioning and transferring patients can be seen frequently. Although the duration of lifting can be short, the frequency of this activity is high, making the risk of workrelated musculoskeletal disorder is high ${ }^{11}$. Table 2 shows bed areas measured in this study. Hospital $C$ has the smallest bed area, compares to Hospital $E$ that has ample space of $11.4 \mathrm{~m}^{2}$. 
Table 2: Bed area at red zone

\begin{tabular}{cc}
\hline Hospital & $\begin{array}{c}\text { Bed space areas } \\
(\mathrm{m} 2)\end{array}$ \\
\hline A & 7.8 \\
B & 10.2 \\
C & 2.88 \\
D & 4.37 \\
E & 11.4 \\
\hline
\end{tabular}

The observation proved that there are many essentials trolleys and equipment kept around the bed space. Nevertheless, some equipment is used frequently, but some are not. The placement of trolley and equipment has crowded the already small space, especially for Hospital C and $\mathrm{D}$. The similar issue also happened in intensive care unit, resulting in the same hazard ${ }^{7}$. Due to this, other hazard might have the risk of occurrence, such as slip-trip-fall. In most emergency situation, some other equipment will be brought into the red zone to assist in patient management such as ultrasound machine or intubation apparatus. The additional machines in already small area causes more risk of trip and hazard and discomfort for the healthcare worker.

\section{Monitor height}

The important of monitors at red zone of emergency department are undeniable. Patient's vital signs and progress are shown on the monitor's screen. Medical officers and nurses refer to the monitor frequently especially when dealing with critically ill and life-threatening condition's patients. Thus, the monitor is undeniably important equipment in the management of patient in the red zone. To date, there is not standard height of the placement of monitor in the red zone of accident and emergency department. Most of the time, the monitor are fixed to the height that pre determine by the company who fix the item upon purchase and on suggestion of certain parties base their preference rather than research base for users. Table 3 shows height of monitors at participating red zones.

Table 3: Monitor Heights

\begin{tabular}{cc}
\hline Hospital & $\begin{array}{c}\text { Monitor Height } \\
(\mathrm{m} 2)\end{array}$ \\
\hline & 1.6 \\
A & 2.16 \\
B & 1.85 \\
C & 2.1 \\
D & 1.9 \\
E & \\
\hline
\end{tabular}

Based on Malaysia anthropometrics data, mean standing eyes height for male Malaysian citizen is
$1521.04 \mathrm{~mm}(1.52104 \mathrm{~m})$ and for female Malaysian citizen is $1520.66 \mathrm{~mm}(1.52066 \mathrm{~m})^{8}$. Comparing Table 3 with mean standing eyes height for Malaysian, the height of monitor for all red zone are higher. This will lead to increase of discomfort when the healthcare workers required to look at the monitor, frequently. Furthermore, none of the monitor's height is adjustable.

\section{ETHICAL APPROVAL}

Ethical approval is obtained from University Hospital and Ministry of Health via application in NMMR. The study is only conducted when the ethical application is approved. In addition, head department of related accident and emergency department are contacted, approval and appointment are made earlier before the visit.

\section{DISCUSSION}

Findings show red zone of accidents and emergency department of Malaysian Hospitals involved in the study are not operating at optimum conditions, as compared to guidelines and suggestions from literature. For lighting, immediate change can be made by adding more lamps to improve the condition. However, the practical solution is to embed the need of lighting during design stage. Similarly with the bed space, the current conditions of space at all red zones involved in the study did not permit for further expansion, in terms of space. The area in red zone is limited with multiple equipment and trolleys around. Thus, it is crucial to consider the proper sizing of bed area during design stage when designing new hospital. As for monitor height, the solution is to change the height of the current monitor to the appropriate height, as mentioned. In addition, healthcare worker, need to be aware that they are working in an environment hazardous to their health. Awareness program should be introduced in order to increase the awareness among them. With awareness, they will be able to channel complaint and appropriate suggestions in order to improve their working conditions.

\section{CONCLUSION}

The physical condition at the red zone is not standardized, in terms of luminance, bed space, equipment arrangement and monitors height. To conclude the physical condition only lead to musculoskeletal disorder might not be adequate since some red zone has better environment than the other. Therefore, further research needs to be done in order to determine the optimal condition at red zone that can reduce the risk of musculoskeletal disorder among the healthcare workers. This will require top-bottom approach because it will involve budgeting. Furthermore, 
some changes especially for bed space area might be difficult to be done at existing red zone and more suitable to be considered and implemented during design stage of new red zone.

\section{ACKNOWLEDGEMENTS}

The authors wish to thank the staffs and facilities for all the hospitals involved in providing assistance in this study.

\section{COMPETING INTERESTS}

There is no conflict of interest.

\section{REFERENCES}

1. J. Bartnicka, "Knowledge-based ergonomic assessment of working conditions in surgical ward - A case study," Saf. Sci., 2015.

2. A. Jellad, H. Lajili, S. Boudokhane, H. Migaou, S. Maatallah, Z. Ben, and S. Frih, "Musculoskeletal disorders among Tunisian hospital staff: Prevalence and risk factors," EJR, vol. 35, pp. 59-63, 2013.

3. S. Meksawi, B. Tangtrakulwanich, and V. Chongsuvivatwong, "Musculoskeletal problems and ergonomic risk assessment in rubber tappers: A community-based study in southern Thailand," Int. J. Ind. Ergon., 2012.

4. G. H. Schierhout, J. E. Myers, and R. S. Bridger, "Musculoskeletal pain and workplace ergonomic stressors in manufacturing industry in South Africa," Int. J. Ind. Ergon., 1993.
5. G. H. Schierhout, J. E. Myers, and S. Bridger, "Musculoskeletal pain and workplace ergonomic stressors in manufacturing industry in South Africa," vol. 12, pp. 3-11, 1993.

6. L. B. M. de Guimarães, M. J. Anzanello, J. L. D. Ribeiro, and T. A. Saurin, "Participatory ergonomics intervention for improving human and production outcomes of a Brazilian furniture company," Int. J. Ind. Ergon., 2015.

7. M. Alameddine, K. N. Dainty, R. Deber, and W. J. (Bill) Sibbald, "The intensive care unit work environment: Current challenges and recommendations for the future," Journal of Critical Care. 2009.

8. R. F. Gulrajani, "Physical environmental factors affecting patients ' stress in the Accident and Emergency department," no. I 995, pp. 22-27.

9. S. G. Tziaferi, P. Sourtzi, A. Kalokairinou, E. Sgourou, E. Koumoulas, and E. Velonakis, "Risk Assessment of Physical Hazards in Greek Hospitals Combining Staff' s Perception, Experts' Evaluation and Objective Measurements," Saf. Health Work, vol. 2, no. 3, pp. 260-272, 2011.

10. S. Hignett and J. Lu, "Space to care and treat safely in acute hospitals: Recommendations from 1866 to 2008," Appl. Ergon., 2010

11. E. M. Eatough, J. D. Way, and C. H. Chang, "Understanding the link between psychosocial work stressors and workrelated musculoskeletal complaints," Appl. Ergon., 2012. 